\title{
Greenhouse Gas Emissions Quantification and Reduction Efforts in a Rural Municipality
}

\author{
Andreas Froemelt, Manuela Mauchle, Bernhard Steubing, and Stefanie Hellweg
}

\section{Keywords:}

carbon footprint consumption-based footprint greenhouse gas emissions industrial ecology purely geographical accounting rural areas

江

Supporting information is linked to this article on the JIE website
$\Gamma$

\begin{abstract}
Summary
The present article aims to determine the current carbon footprint (CF) of Zernez, a Swiss mountain village, and to identify reduction potentials of greenhouse gas (GHG) emissions. For this purpose, material and energy flows were assessed mainly based on detailed household surveys, interviews, and energy bills, but also by means of other information sources, for example, national statistics, traffic censuses, and literature values. To set up the GHG balance, special attention was paid to the consistent definition of system boundaries by adopting two fundamentally different perspectives: purely geographical accounting (PGA) and the consumption-based footprint (CBF) method. Each of these two perspectives total approximately 10 tonnes of carbon dioxide equivalents per capita per year. The PGA revealed that $70 \%$ of the direct emissions in Zernez are caused by agricultural activities, whereas no consumption area dominated the consumption-induced CF. For the identification of targeted measures, both perspectives were considered in a complementary manner. The building stock and its underlying energy supply system showed a GHG reduction potential of $80 \%$. The building sector was thus detected as a reasonable first step for the municipality to adopt GHG mitigation strategies. In the case of Zernez, building-stock-related measures are predicted to decrease the current CF by I3\% (CBF) and I7\% (PGA), respectively.
\end{abstract}

\section{Introduction}

Urban and rural settlements constitute the heart of human activities and are thus central sources of anthropogenic greenhouse gas $(\mathrm{GHG})$ releases. Local initiatives to reduce GHG emissions from human settlements are essential to abate climate change (UN-HABITAT 2011). In view of the important role that $\mathrm{GHG}$ accounting plays in the planning process of mitigation measures, a large body of carbon footprint (CF) studies on different scales has evolved, among them Kennedy and colleagues $(2009,2010,2014)$, Frischknecht and colleagues (2014), Minx and colleagues (2013), Goldstein and colleagues (2013), Jungbluth and colleagues (2011), Larsen and Hertwich (2010), Hertwich and Peters (2009), Hillman and Ramaswami
(2010), and Ramaswami and colleagues (2008). Most of these studies concentrate on nations or cities. Given that around half of the global population currently lives in urban areas, with this share rapidly increasing in the future (UN 2012), many researchers (e.g., Kennedy et al. 2009, 2010, 2014; Goldstein et al. 2013; Baynes et al. 2011) emphasize that a focus on cities is crucial. Whereas the present and future importance of urban settlements is unquestionable, it should not be overlooked that a large part of the world's population continues to live in the countryside. This is also true for both developing and industrialized nations. For instance, according to the "Degree of Urbanization (DEGURBA)" definition of the European Union (Eurostat 2016), approximately 65\% of all Swiss municipalities are classified as "thinly populated" and are home to around $25 \%$

Address correspondence to: Andreas Froemelt, ETH Zurich, Institute of Environmental Engineering, Ecological Systems Design, HPZ E32.2, John-von-Neumann-Weg 9, CH-8093 Zurich, Switzerland. Email: froemelt@ifu.baug.ethz.ch 
of the Swiss population (BFS 2014a, 2014b). However, CF studies and local GHG mitigation initiatives in rural contexts are, to the best of our knowledge, less common (Minx et al. 2013).

All of the above-mentioned CF studies had to deal with an important question: how to set the system boundaries to adequately account for GHG emissions. This is an ongoing debate and different frameworks have emerged. Lin and colleagues (2015), Chavez and Ramaswami (2013), Baynes and Wiedmann (2012), and Ramaswami and colleagues (2011, 2012) provide comprehensive overviews of state-of-the-art carbon balancing approaches. According to these studies, there are basically two fundamentally different accounting perspectives (some aforementioned articles distinguish more): the consumption-oriented $\mathrm{CF}$ and the production-based approach. The first corresponds to a life cycle perspective and focuses on global GHG releases induced by the consumption behavior of the inhabitants living within the study area. In contrast, emissions related to activities and processes taking place within the study boundaries are the center of focus in production-based accounting schemes. The narrowest scope of a production-based accounting method accords with a territorial approach and concentrates solely on direct emissions within the geographical boundaries of the study area. This balancing scheme is often encountered in national-scale footprints and conforms to the so-called Scope 1 perspective of the World Resources Institute/World Business Council for Sustainable Development (WRI/WBCSD) (2004). Some studies (Ramaswami et al. 2008; Kennedy et al. 2009, 2010, 2014; Hillman and Ramaswami 2010; Lin et al. 2015) broaden this territorial inventory viewpoint to a "geographic-plus" (Ramaswami et al. 2011; Baynes and Wiedmann 2012) or "trans-boundary community-wide infrastructure" footprint (Chavez and Ramaswami 2013; Lin et al. 2015) by including Scope 2 (indirect emissions from electricity production) and Scope 3 emissions (indirect emissions from other key flows into the study area) (WRI/WBCSD 2004). By concentrating on key infrastructure, this approach is especially useful for urban planners and facility managers.

The choice of a GHG accounting scheme depends on the question one seeks to answer. However, it is important to be consistent within the chosen approach. As stated by several researchers (Ramaswami et al. 2011, 2012; Baynes et al. 2011; Baynes and Wiedmann 2012; Lin et al. 2015), consumption-based and production-based accounting methods are complementary to each other. The consumption perspective supports the identification of measures without problem shifting by pursuing a life cycle perspective. Moreover, it facilitates the derivation of policies aimed at influencing consumption behavior (Baynes and Wiedmann 2012). By quantifying direct emissions within the geographical system boundaries, a purely territorial inventory pinpoints areas of action for local authorities because it takes into account the local conditions. Both accounting frameworks hence provide important insights for local policy making from different viewpoints.
The Swiss mountain village of Zernez initiated the research project Zernez Energia 2020 to identify ways to reduce its GHG emissions using both a consumption-based footprint and a purely geographical accounting. The assessment of the municipality's CF is an important first step in the project and is presented in this article. The analysis of the current $\mathrm{CF}$ allows for identifying the most relevant actors and sectors regarding GHG emissions as well as for discussing GHG reduction potentials. It also serves as a planning basis for the municipality of Zernez with the aim of developing a concrete action plan to implement GHG mitigation measures. This study can provide a baseline for similar studies in other municipalities and fills a knowledge gap by delivering insights into the CF of a village in an industrialized country. Additionally, there are advantages in focusing on a small village. Whereas many large-scale studies struggle with data scarcity, the limited size of Zernez allows, for example, for data collection through detailed surveys of all households and buildings in the village. Surveys with $100 \%$ coverage, as in the present study, are extremely rare. Therefore, the present study provides also a unique occasion for an in-depth analysis of a rural community.

The goal of the present article is twofold: It aims to assess the CF of Zernez as well as to discuss its GHG reduction potentials. Moreover, it intends to provide an insight into a rural area's CF based on a unique data set.

\section{Methodology \\ System Boundaries}

The municipality of Zernez, which was home to 1,140 inhabitants (BFS 2014c) in the year 2010, is situated in the Swiss Alps at an average altitude of 1,471 meters with an area of 203.85 square kilometers (see the Supporting Information available on the Journal's website for a map) (swisstopo 2014). Hosting large parts of the Swiss National Park, Zernez belongs to the largest municipalities in Switzerland in terms of land area.

The geographical system boundaries focused on the settlement area of the village's core with 1,003 residents. Additionally, all agricultural and forest areas within the municipal borders and managed by these persons or by the municipality were included in the analysis. Hamlets and remote single houses located within the municipality's borders as well as the Swiss National Park were excluded from consideration.

In view of the specific benefits of the two GHG accounting schemes, the CF of Zernez was assessed simultaneously by a production-based territorial inventory (only Scope 1/direct emissions) and from a consumption-based perspective (life cycle emissions from final consumption). Following the definitions given by Lin and colleagues (2015), these applied accounting methods will be called henceforth "purely geographical accounting" (PGA) and "consumption-based footprint" (CBF), respectively.

Computations and analyses of the present article refer, whenever possible, to the year 2010. 


\section{Categories Emission Classes}

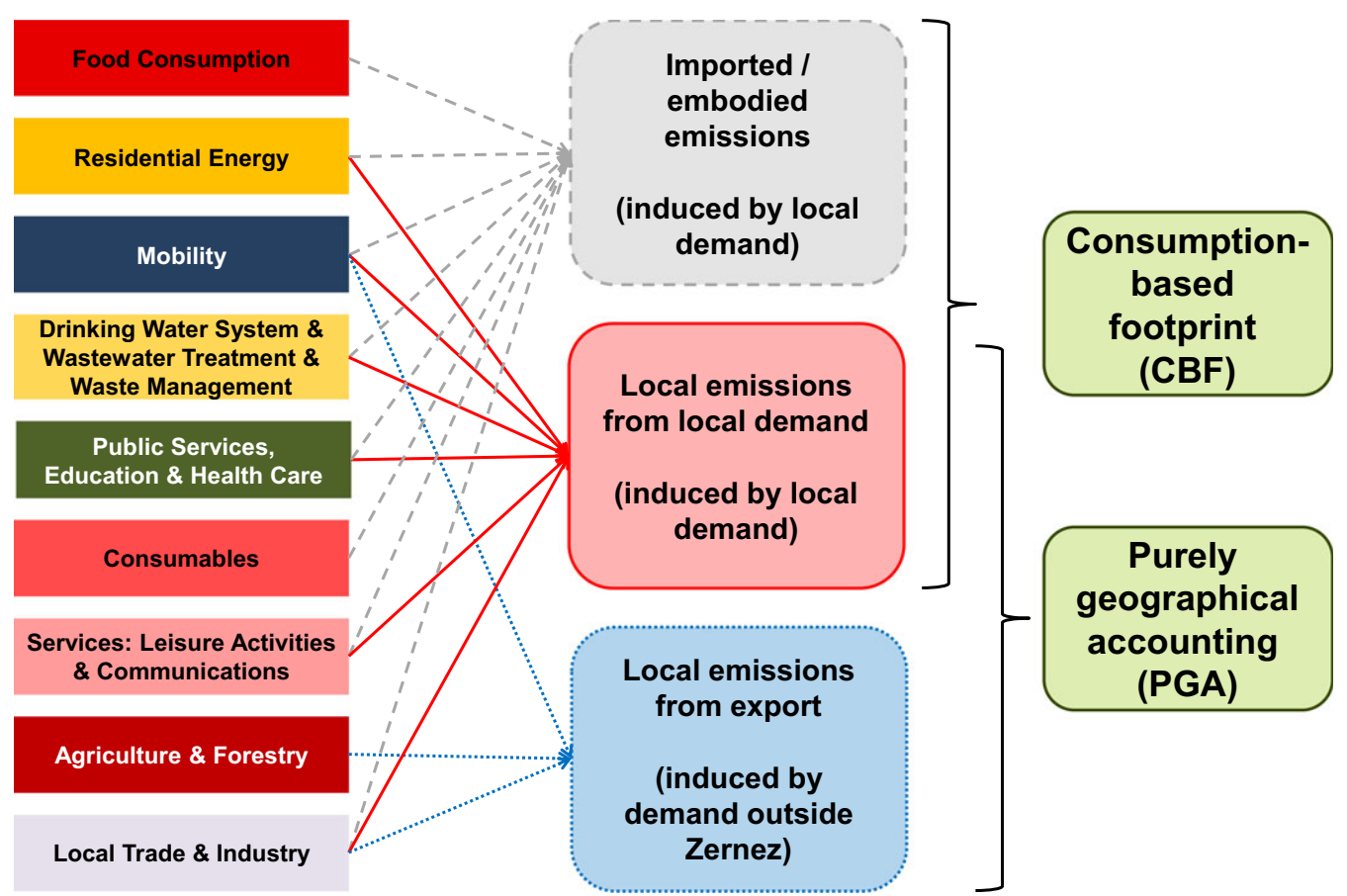

Figure I Schematic overview of the allocation of GHG emissions from different categories to emission classes ("imported emissions," "local emissions from local demand," and "local emissions from export"). The figure also shows how emission classes add up to CBF and PGA. GHG = greenhouse gas.

\section{Overview of the Applied Greenhouse Gas Accounting Approach}

In a preparatory step, all processes, activities, materials, and energy flows that are relevant for the municipality's CF were identified. This systematic identification process was conducted in close collaboration with the municipality and built upon similar studies (Jungbluth et al. 2011, 2012; BFS 2014d). All processes and flows were then classified into nine categories (left part of figure 1).

In order to set up the GHG balance according to $\mathrm{CBF}$ and PGA, a three-tiered approach was applied. First, the magnitude of all flows belonging to the above-mentioned nine categories was quantified. For example, in the category residential energy, this includes the amounts of electricity and fuels needed to provide buildings with heat. Second, the GHG emissions of these quantified entities were estimated based on life cycle inventory (LCI) databases, such as ecoinvent (ecoinvent Center 2013). Thereby, the CF of an activity is assessed on the basis of the global warming potentials published by the Intergovernmental Panel on Climate Change (IPCC) (2007) for a time horizon of 100 years.

In the third step, the GHG emissions of each of the modeled activities were classified into the following three emission classes (figure 1, center): emissions outside Zernez caused by the consumer demand of the inhabitants ("imported/embodied emissions"); emissions released within the geographical system boundaries that occur on account of the consumption behavior of the people in Zernez ("local emissions from local demand"); and emissions released within the geographical system boundaries, but induced by the demand of consumers outside Zernez ("exported emissions").

The use of background data from LCI databases results in life cycle GHG emissions for the modeled processes. For the aforementioned classification into emission classes, which is schematically illustrated in figure 1, this assessment of life cycle GHG emissions had thus to be split into local emissions and emissions occurring upstream in the supply chain. Thereby, the latter is allocated to the embodied emissions given that these emissions occur outside the village. However, imported/embodied emissions do not include re-exported embodied emissions because these GHG are not induced by the inhabitants of Zernez. An overview of the most important assumptions with regard to this classification can be found in the Supporting Information on the Web.

The distinction into three emission classes allowed for appropriately summing up to CBF and PGA, respectively (figure 1, right).

All of these three steps (quantification of flows, assessment of GHG emissions, and allocation of emissions to emission classes) are explained in more detail in the subsequent section. Note that, in this article, "imports" and "exports" do not refer to a national level, but describe goods entering and leaving the municipal boundaries. 


\section{Quantification and Modeling of Activities}

A bottom-up approach was followed in the data collection for the quantification of material and energy flows. Within the scope of the project, surveys and interviews were conducted and energy bills and municipal statistics were gathered. A large part of the collected data was compiled into a building database containing comprehensive information about energy consumption as well as specific data for all buildings in the municipality (Wagner et al. 2015a). This database is unique in terms of full coverage of buildings and represents one of the most important data sources for the present study. The combination of this database with energy bills and a census of enterprises (see the Supporting Information on the Web) provided data on final energy demand of all households and enterprises in the village. The building database scheme as well as further details on other bottom-up data used for the present study (e.g., operation information of district heating network, waste statistics, and information from the forestry administration) are described in Wagner and colleagues (2015a) and in the Supporting Information on the Web. In addition to these data, further interviews were conducted to gain detailed information on the operation of specific facilities in the municipality (e.g., a biogas plant). The whole data set was finally amended by statistics of federal and cantonal offices, federal surveys, traffic censuses, and literature values.

After quantifying the energy and material flows within the municipality, GHG emissions were assessed by adding suitable background data from process-based LCI databases (e.g., ecoinvent Center 2013).

Table 1 provides a brief overview of the used data sources. Further, a detailed list of all modeled activities and data sources used for the estimation of GHG emissions as well as the most important assumptions for the subdivision of emissions into emission classes are documented in the Supporting Information on the Web.

In addition, an independent alternative approach was followed by applying Saner and colleagues' (2013) model to Zernez in order to assess the consumption-related CF in the areas of residential energy and mobility (see the Supporting Information on the Web). This model is able to determine housing and land-based mobility demand of individual households. Because it is mainly based on national databases and simulation results of MATSim (Multi-Agent Transport Simulation) (Balmer et al. 2006; Meister et al. 2010), no extra data acquisition is needed beforehand. MATSim, which is the basis for the mobility submodel, was calibrated and validated for Switzerland (Balmer et al. 2006; Meister et al. 2010), whereas the housing submodel was evaluated by Froemelt and Hellweg (2016).

\section{Food Consumption}

All liquid and solid food has to be "imported" from outside the municipality given that no industrial food processing takes place in Zernez. Because sales data of the two largest local retailers could not be accessed, food consumption was estimated by means of the Swiss Household Budget Survey (HBS) (BFS
2012). Among other things, the HBS provides detailed insight into the quantities of more than 100 different food categories bought by an average Swiss household. This also includes farm gate sales and food produced in gardens. These two food production processes were allocated to "imported/embodied emissions" instead of "local emissions from local demand" because they were assumed to play a minor role and detailed data were lacking. Food consumed in restaurants was estimated by combining the HBS with a survey of the Association for Hotels and Restaurants in Switzerland (GastroSuisse 2012) and the menu cards of local restaurants.

Preparation of food at home or in the restaurants is not accounted for in this category, but covered by the categories residential energy and services: leisure activities and communications (see corresponding sections below).

The life cycle GHG emission factors for food consumption were retrieved from Saner and colleagues (2016), who consolidated different databases and studies (e.g., ecoinvent Center 2013; Thrane 2006; Büsser and Jungbluth 2009; Stoessel et al. 2012). However, these factors include neither transport to the shops nor electricity and space heating demand of the shops. These processes were additionally modeled by electricity bills of the local retailers and by transport distances from the food distribution centers of the respective company to the shop in Zernez.

\section{Residential Energy}

In the scope of the research project Zernez Energia 2020, a survey was conducted in order to collect data on the quantities of energy carriers used, including fuel oil, wood chips, firewood, district heating, and electricity. Besides interviews with all households, the municipality provided detailed electricity and district heating energy bills for all households and enterprises. In addition to final energy consumption data, the municipality and the inhabitants supplied also detailed information on installed heating systems and on different building characteristics. This enabled the setup of a unique database with full coverage of all buildings (Wagner et al. 2015a). More information on this building database as well as on data from electricity bills and the district heating network is presented in the Supporting Information on the Web.

The municipality draws its electricity from two main sources: a power company that delivers certified electricity from a runof-river power plant through the national grid and a reservoir power plant located partly in the municipality. The latter is therefore regarded as locally produced energy. Local electricity is also produced by photovoltaic (PV) systems and a biogas plant; however, this power is exported to the national grid and, consequently, only considered in the PGA. Using a combined heat and power plant, the biogas plant operating on agricultural waste produces heat in addition to electricity. Detailed plant operation information was provided by the owner (Grass 2014).

Data on wood chip supplies for the local district heating network were provided by the operators, the municipality, and the forestry administration (see section on Agriculture and Forestry below as well as the Supporting Information on the Web). 
Table I Overview of the data sources used for the quantity and GHG assessment in the different categories

\begin{tabular}{|c|c|c|c|}
\hline \multirow[b]{2}{*}{ Category } & \multicolumn{2}{|l|}{ Quantity assessment } & \multirow{2}{*}{$\begin{array}{l}\text { GHG assessment } \\
\text { (background data) }\end{array}$} \\
\hline & Data source & Scale of data & \\
\hline \multirow[t]{3}{*}{ Food consumption } & HBS (BFS 2012) & National $^{a}$ & Saner and colleagues (2016) \\
\hline & GastroSuisse (2012) & National $^{\mathrm{a}}$ & ecoinvent Center (2013) \\
\hline & Electricity Bills (Wagner et al. 2015a) & Zernez & \\
\hline \multirow[t]{5}{*}{ Residential energy } & Building Database (Wagner et al. 2015a) & Zernez & ecoinvent Center (2013) \\
\hline & Electricity Bills (Wagner et al. 2015a) & Zernez & \\
\hline & OI DHN (Wagner et al. 2015a) & Zernez & \\
\hline & Forestry Administration (Wagner et al. 2015a) & Zernez & \\
\hline & OI for Biogas Plant (Grass 2014) & Zernez & \\
\hline \multirow[t]{4}{*}{ Mobility } & $\begin{array}{l}\text { Mobility and Transport Microcensus (ARE et al. } \\
\text { 2012) }\end{array}$ & Cantonal $^{\mathrm{b}}$ & ecoinvent Center (2013) \\
\hline & Local Age Structure (AWT 2010) & Cantonal $^{c}$ & \\
\hline & $\begin{array}{l}\text { Automatic Traffic Counters (TBA 2011; ASTRA } \\
\text { 2014) }\end{array}$ & Zernez & \\
\hline & Timetables of PT (PostAuto 2014; SBB 2014) & Zernez & \\
\hline \multirow{3}{*}{$\begin{array}{l}\text { Drinking water and } \\
\text { wastewater system and waste } \\
\text { management }\end{array}$} & Building Database (Wagner et al. 2015a) & Zernez & ecoinvent Center (2013) \\
\hline & Electricity Bills (Wagner et al. 2015a) & Zernez & \\
\hline & OI WWTP (Filli 2014) & Zernez & \\
\hline \multirow{6}{*}{$\begin{array}{l}\text { Public services and health } \\
\text { care }\end{array}$} & Building Database (Wagner et al. 2015a) & Zernez & ecoinvent Center (2013) \\
\hline & Electricity Bills (Wagner et al. 2015a) & Zernez & Jungbluth and colleagues (2011) \\
\hline & OI DHN (Wagner et al. 2015a) & Zernez & \\
\hline & Census of Enterprises (see the Supporting & Zernez & \\
\hline & Information on the Web) & & \\
\hline & Jungbluth and colleagues (2011) & National $^{\mathrm{d}}$ & \\
\hline Consumables & Jungbluth and colleagues (2011) & National $^{\mathrm{d}}$ & Jungbluth and colleagues (2011) \\
\hline \multirow{9}{*}{$\begin{array}{l}\text { Services: Leisure activities } \\
\text { and communications }\end{array}$} & Building Database (Wagner et al. 2015a) & Zernez & ecoinvent Center (2013) \\
\hline & Electricity Bills (Wagner et al. 2015a) & Zernez & König and colleagues (2014) \\
\hline & OI DHN (Wagner et al. 2015a) & Zernez & Jungbluth and colleagues (2011) \\
\hline & $\begin{array}{l}\text { Mobility and Transport Microcensus (ARE et al. } \\
\text { 2012) }\end{array}$ & Cantonal $^{\mathrm{b}}$ & \\
\hline & Survey of Travels of Swiss Residents (BFS 2011) & National $^{\mathrm{a}}$ & \\
\hline & Local Age Structure (AWT 2010) & Cantonal $^{\mathrm{c}}$ & \\
\hline & OI Swiss Post (Saner 2014) & Zernez & \\
\hline & Census of Enterprises (see the Supporting & Zernez & \\
\hline & Jungbluth and colleagues (2011) & & \\
\hline \multirow[t]{3}{*}{ Agriculture and forestry } & $\begin{array}{l}\text { Census of Enterprises (see the Supporting } \\
\text { Information on the Web) }\end{array}$ & Zernez & ecoinvent Center (2013) \\
\hline & Farm Structure Survey (BFS 2014a) & National $^{\mathrm{c}}$ & Nielsen and colleagues (2003) \\
\hline & Forestry Administration (Wagner et al. 2015a) & Zernez & \\
\hline \multirow[t]{7}{*}{ Local trade and industry } & Building Database (Wagner et al. 2015a) & Zernez & ecoinvent Center (2013) \\
\hline & $\begin{array}{l}\text { Census of Enterprises (see the Supporting } \\
\text { Information on the Web) }\end{array}$ & Zernez & Jungbluth and colleagues (2011) \\
\hline & Electricity Bills (Wagner et al. 2015a) & Zernez & \\
\hline & OI DHN (Wagner et al. 2015a) & Zernez & \\
\hline & OI Gravel Quarry (SOSA GERA SA 2014) & Zernez & \\
\hline & OI Swiss Post (Saner 2014) & Zernez & \\
\hline & Jungbluth and colleagues (2011) & National $^{\mathrm{d}}$ & \\
\hline
\end{tabular}

a Adjusted for Zernez (e.g., by taking local age structure into account; see text for more information).

${ }^{\mathrm{b}}$ Adjusted to represent the canton's rural areas and adjusted for Zernez by taking into account the local age structure.

'Specifically retrieved for Zernez from a national or cantonal database.

${ }^{\mathrm{d}}$ Scaled down to Zernez on a per-capita basis.

$\mathrm{HBS}=$ Swiss Household Budget Survey; OI = operation information; DHN = district heating network; PT = public transportation; WWTP = wastewater treatment plant. 
Imported firewood was calculated as the difference between used amounts of log wood and the amount of firewood sold by the forestry administration (Wagner et al. 2015a).

In order to model the energy supply for residential buildings in detail, suitable ecoinvent processes were chosen and adjusted (ecoinvent Center 2013). The building database, as well as the information above, was also used to model building-energyrelated parts of the categories public services, education, and health care, services: leisure activities and communications, and local trade and industry (see sections below).

\section{Mobility}

The Mobility and Transport Microcensus of the canton of Grisons provides comprehensive insight into the mobility behavior of the canton's population (ARE et al. 2012). Because the municipality of Zernez is located in a rural area of Grisons, the canton's only region with an urban character (the city of Chur) was separated and removed from the results of the $\mathrm{Mi}$ crocensus. Details on chosen traffic modes, distances driven, as well as purpose and character of trips were deduced for different age cohorts representing the canton's rural population. To set up the carbon balance for the CBF, these results were applied to Zernez by taking into account the local age structure (AWT 2010).

A totally different approach had to be chosen for the PGA. In this view, the mobility demands of the inhabitants are not of interest, but instead the traffic volume within the municipality's borders. For this purpose, automatic traffic counters (operated by the cantonal administration) were analyzed (TBA 2011; ASTRA 2014). Public transportation within the municipality was assessed by means of timetables and route information (PostAuto 2014; SBB 2014).

For the allocation of GHG to emission classes according to figure 1 , both approaches needed to be combined. The information provided by the Microcensus includes data on distances, duration, traffic mode, as well as purpose and number of trips. This allowed for estimations of trips within the municipal geographical boundaries and therefore to assess "local emissions from local demand." These emissions were then subtracted from the above-described total mobility CBF and total mobility PGA, leaving the remainder as the "imported/embodied emissions" and the "local emissions from export," respectively.

\section{Drinking Water System, Wastewater Treatment, and Waste Management}

The municipality's drinking water system is composed of two spring water catchments, one groundwater pumping station and one reservoir to which the water has to be pumped. No further treatment steps are needed. Together with the electricity demand of the pumps in 2010, the drinking water system could be modeled with ecoinvent activities (ecoinvent Center 2013).

In order to represent the wastewater treatment plant (WWTP), ecoinvent activities (ecoinvent Center 2013) were adjusted and remodeled according to interviews with operators and operating data (Wagner et al. 2015a; Filli 2014). Biogas produced in an anaerobic digester was used to satisfy parts of the
WWTP's heating demand. Usually, excess biogas is converted into electricity and exported to the national grid. However, in the year 2010, the WWTP heating demand exceeded biogas production and was supplemented by burning fuel oil.

Detailed data were available to represent the waste management system (see the Supporting Information on the Web) (Wagner et al. 2015a). Municipal solid waste (MSW), cardboard, paper, and waste glass are separated by the citizens and then collected regularly by a garbage truck. After trans-shipping to a freight train, MSW is transported to an MSW incinerator, whereas cardboard, paper, and waste glass are conveyed to recycling processes. Background data were taken from ecoinvent (ecoinvent Center 2013).

\section{Public Services, Education, and Health Care}

Public services subsume all services from governmental institutions, excluding waterworks, wastewater system, and waste management (already covered by the section above). Local emissions stemming from the operation of public buildings could be assessed based on the building database (cf. section on Residential Energy) and a census of enterprises (cf. the Supporting Information on the Web). However, many of the emissions from the public sector, for example, those caused by the operation of federal offices or by the national defense, have to be allocated to all Swiss inhabitants. Therefore, Swiss average values were applied from Jungbluth and colleagues (2011) to cover remaining emissions of this category, all of which were assumed to take place outside the village. Swiss average values were also used for emissions from education and health care (Jungbluth et al. 2011).

\section{Consumables}

Very little data were available for consumables such as clothing, furniture, and domestic appliances. Just as comestible goods, these products are mostly imported to Zernez. Therefore, Swiss average values retrieved from Jungbluth and colleagues (2011) were used for this consumption area.

\section{Services: Leisure Activities and Communications}

This section encompasses all services consumed that are not already covered in other categories. For instance, recreational traffic is accounted for in mobility, food consumption includes eating out, and the consumables category already accounts for leisure equipment.

An estimation of the residents' leisure behavior was facilitated by the Microcensus (ARE et al. 2012) from which information on purpose and destination of the residents' trips could be retrieved. A combination of this information with the estimation of trips within the geographical system boundaries (see section Mobility), a census of enterprises (cf. the Supporting Information on the Web), and further interviews (e.g., with the operators of the indoor hot spa swimming pool regarding the number of sold tickets) allowed for a rough assessment of leisure services consumed within Zernez by residents and thus the computation of "local emissions from local demand." 
Vacations are an important area not included in other categories. The Swiss Federal Statistical Office published data on the travel patterns of the Swiss population, including number of trips, duration of trips, destinations, and number of hotel overnight stays (BFS 2011). Because this statistical analysis was performed for different age groups, the data could be used to determine the vacations of people from Zernez by considering the local age structure (AWT 2010). A study that assessed GHG emissions for different vacation scenarios (König et al. 2014) was adjusted and used for GHG intensity factors for hotel overnight stays.

Further services considered in this category are newspaper consumption, which was modeled by ecoinvent activities (ecoinvent Center 2013) and data from the Swiss Post (Saner 2014), as well as communications. For the latter, Swiss average values from Jungbluth and colleagues (2011) were applied because no specific data were available for Zernez and because it is plausible to assume that people in Zernez behave similarly and cause similar emissions in terms of communications as the Swiss average citizen.

\section{Agriculture and Forestry}

Just as in most other Alpine regions, livestock farming dominates Zernez's agricultural sector.

Arable farming was negligibly small (total arable area in Zernez is only 4.2 hectares) (BFS 2014c) and not further considered. A list of all animals kept in the municipality was obtained from the Farm Structure Survey of the Swiss Federal Statistical Office (BFS 2014c). Building upon this information and in combination with a census of enterprises (cf. the Supporting Information on the Web), the agricultural sector was modeled by adjusting appropriate processes of ecoinvent (ecoinvent Center 2013) and the life cycle assessment food database (Nielsen et al. 2003).

The municipal forestry administration provided detailed data on sales of firewood, trunk wood, wood chips, and other unspecified wood (see Wagner et al. [2015a] and the Supporting Information on the Web). Ten percent of the trunk wood is processed by the forestry administration themselves, whereas the rest is sent to different sawmills in Switzerland, Austria, and Italy. Operating records on amounts of diesel and petrol used were available. The forestry sector was then modeled by adapting ecoinvent activities (ecoinvent Center 2013) accordingly.

\section{Local Trade and Industry}

According to the census of enterprises (cf. the Supporting Information on the Web), local trade comprises mostly restaurants, hotels, offices, and local retailers. Direct emissions induced by tourism, an important economic sector for Zernez, are thus accounted for in this category. Most emissions caused by the aforementioned industries are determined by modeling the respective energy use based on combining the building database (cf. section on Residential Energy) with the census of enterprises (cf. the Supporting Information on the Web).

Two important enterprises, a large gravel quarry and the office of the Swiss Post, were assessed in more detail. For the post office, detailed data regarding information about amounts of letters, parcels, transport distances, and means of transportation were available from interviews with the sustainability department of the Swiss Post (Saner 2014). This allowed for a detailed modeling of the Post's activities. For modeling the gravel quarry (SOSA GERA SA 2014), an appropriate ecoinvent activity (ecoinvent Center 2013) was chosen.

Housing construction is also included in this category. Though local companies are often responsible for on-site building construction, most emissions from these activities are generated in the supply chain outside of the municipal geographical boundaries through the production of construction materials. Because of a lack of more-detailed data, the modeling of housing construction was based on Swiss average values (Jungbluth et al. 2011). Building upon the findings of Zhang and colleagues (2013), we assumed that $10 \%$ of these construction emissions are released locally.

\section{Results and Discussion}

Figure 2 (top) shows the split of the total GHG into embodied emissions, direct emissions induced by local demand, and exported emissions. These emissions are then summed appropriately in order to represent the CBF and the PGA, respectively. In figure 2 (bottom), the results for these two accounting methods were divided by the number of inhabitants. This normalization facilitates the comparison of the results with other CF studies.

Even though the two viewpoints are fundamentally different, the result of the consumption perspective (9.9 tonnes of carbon dioxide equivalents per person per year $\left[\mathrm{t} \mathrm{CO}_{2}\right.$-eq/(cap·yr)]) is-by coincidence-similar to the production perspective (10.6 t CO $\mathrm{CO}_{2}$-eq/(cap·yr)) in the case of Zernez. Thereby, embodied emissions, taking place outside the municipal boundaries of Zernez, account for around $85 \%$ of the total consumption $\mathrm{GHG}$, whereas exported emissions represent also approximately $85 \%$ of the total territorial GHG emissions. These figures confirm that this small Alpine village is not self-sustaining, but highly integrated in the Swiss and global economy.

\section{Purely Geographical Accounting}

The PGA quantifies direct emissions in Zernez and therefore identifies the most important local GHG emitters. Figure 2 (bottom) reveals that the agriculture and forestry sector clearly dominates the PGA and causes 70\% of the direct GHG releases. Thereby, agricultural activities are responsible for more than $99 \%$ of the total GHG emissions in this category, especially attributed to large enteric methane $\left(\mathrm{CH}_{4}\right)$ emissions and nitrous oxide $\left(\mathrm{N}_{2} \mathrm{O}\right)$ releases stemming from livestock farming. This means that the territorial and the consumption perspective differ also in the composition of GHGs. Whereas the former shows a large share of $\mathrm{CH}_{4}$ and $\mathrm{N}_{2} \mathrm{O}$ emissions, the latter is rather dominated by $\mathrm{CO}_{2}$ releases. 


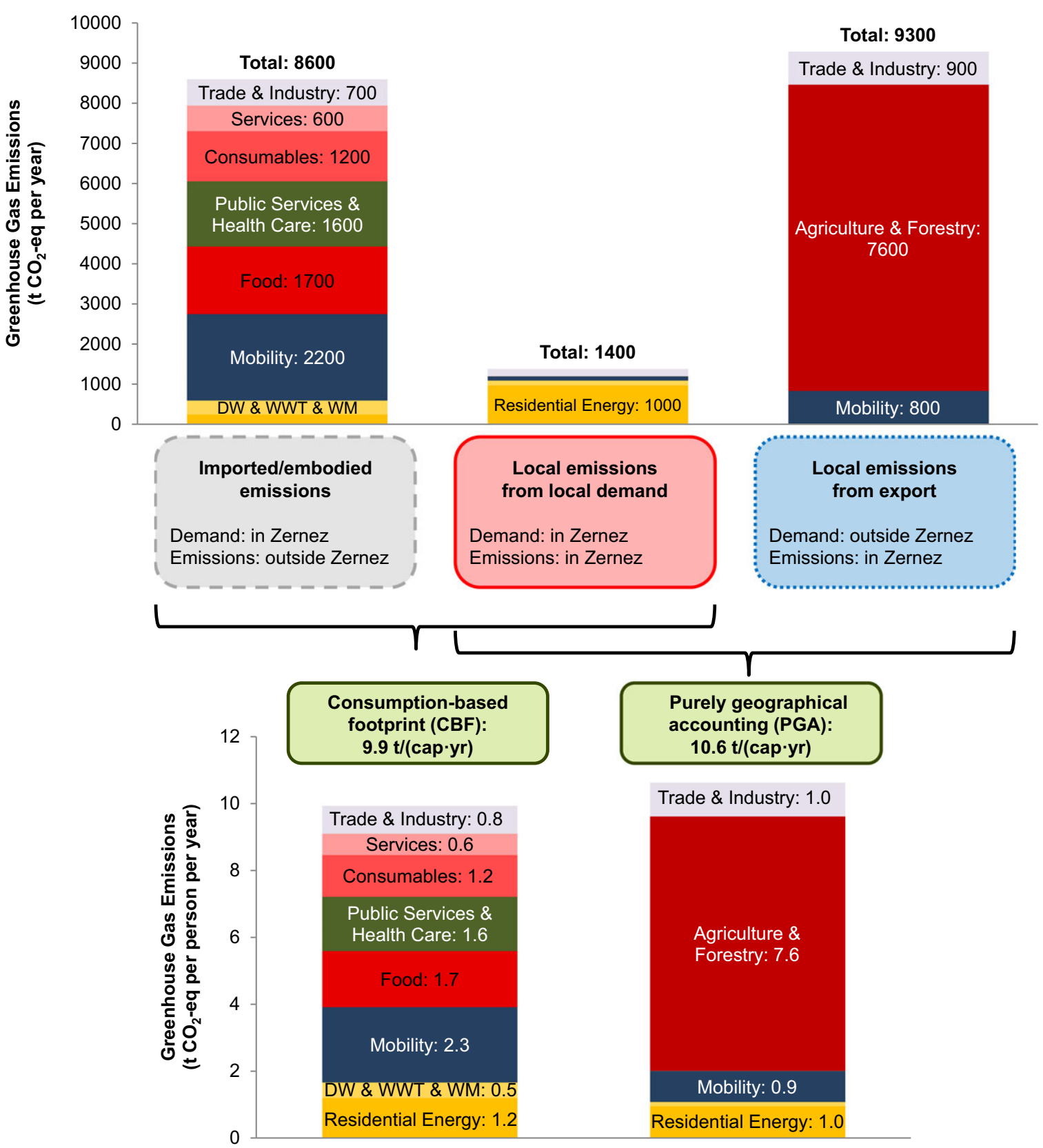

Figure 2 Top: Total GHG emissions divided into "embodied emissions," "local emissions from local demand," and "exported emissions." Bottom: Per-capita carbon footprint of Zernez according to the CBF and the PGA, respectively. Values are rounded to 100 t $\mathrm{CO}_{2}$-eq/yr or 0.1 t CO 2 -eq/(cap·yr). The category services includes leisure activities and communications. DW \& WWT \& WM $=$ drinking water system, wastewater treatment, and waste management; $\mathrm{GHG}=$ greenhouse gas; $\mathrm{t} \mathrm{CO}_{2}$-eq/yr = tonnes of carbon dioxide equivalents per year; $\mathrm{t}$ $\mathrm{CO}_{2}$-eq/(cap·yr) $=$ tonnes of carbon dioxide equivalents per capita per year.

\section{Consumption-Based Footprint}

The CBF provides a life cycle perspective of the consumer behavior. It encompasses all GHG emissions worldwide induced by the demand of the people living within the geographical system boundaries. The consumption-caused total life cycle GHG emissions in Zernez are approximately $22 \%$ below the Swiss average of $12.8 \mathrm{t} \mathrm{CO}_{2}$-eq/(cap.yr) according to Jungbluth and colleagues (2012) (please see the Supporting Information on the Web for a graphical comparison of Zernez's CBF with the national CBF of Switzerland).

Though mobility spearheads GHG emissions, all categories are of similar importance (see figure 2). Many studies (Jungbluth et al. 2007, 2011, 2012; Hertwich and Peters 2009) identify food consumption, mobility, and housing (here, the sum of residential energy and drinking water system, wastewater treatment, and waste management) as the most important consumption domains from an environmental viewpoint. These three categories are 
responsible for more than 50\% of Zernez's GHG emissions; however, they do not outstrip the other categories.

Mobility GHG emissions in Zernez (2.3 t $\mathrm{CO}_{2}$-eq/(cap-yr)) correspond well to the Swiss average of $2.4 \mathrm{t} \mathrm{CO}_{2}$-eq per person per year (Jungbluth et al. 2012). Motorized private transportation is responsible for more than $70 \%$ of the Swiss mobility emissions; however, its contribution in Zernez amounts to more than $85 \%$.

Despite the prevailing cold climate (mean annual air temperature is approximately $5^{\circ} \mathrm{C}$ ) (Orehounig et al. 2014), housinginduced GHG emissions (comprising the categories of residential energy and drinking water system, wastewater treatment, and waste management) in Zernez average out to 1.7 t $\mathrm{CO}_{2}$-eq/(cap.yr) and are considerably below the national mean of $3.0 \mathrm{t} \mathrm{CO}_{2}$ eq/(cap.yr) (Jungbluth et al. 2012). This large deviation can be explained by two main reasons: First, oil boilers cause around $90 \%$ of the residential energy GHG, but only supply around $40 \%$ of the local heat demand for space heating and hot water. A large amount of the local heat demand is covered by wood-based and direct electric heating systems (around 30\% and 20\%, respectively), both of which involve low GHG emissions. Second, electricity is exclusively supplied by hydropower plants, which exhibit very low carbon intensities.

Part of the deviation of Zernez's CF from the national average may also be explained by different methodological approaches, such as different GHG emission factors or different reference years. The areas of housing and mobility were double-checked with the model of Saner and colleagues (2013) and revealed to be consistent with the model results (for further results, see the Supporting Information on the Web).

\section{Identification of Greenhouse Gas Reduction Potentials}

Although the political system in Switzerland grants some liberties to municipalities, their ability to implement measures to reduce GHG emissions is nevertheless limited. They may extend their own infrastructure, provide advice to consumers in different areas, and are free to set financial incentives. But taxes or mandatory measures are usually introduced at national or cantonal levels and only exceptionally at the municipal stage. Making laws stricter is possible for municipalities in some domains, but depends strongly on the canton. Facing this restrictive scope of action, areas susceptible to municipal policies, consumer-driven areas, and areas of supraregional importance are distinguished in order to discuss sectors where the municipality could intervene. On account of their complementary nature, the following discussion examines simultaneously both footprints, PGA and CBF.

\section{Areas Susceptible to Municipal Policies}

The municipality has the ability to reduce mobility emissions through awareness-raising campaigns (e.g., promoting the use of bikes or public transportation or the avoidance of air travels), financial incentives (e.g., for energy efficient and electric vehicles), or an extension of public transportation possibilities. However, decreasing GHG emissions through improved public transport services needs a careful optimization of timetables in order to increase the occupancy of trains and buses. This requires a supraregional perspective, usually lying with the respective railway/bus companies and not directly with the municipality. Implementation of a car sharing system could reduce GHG stemming from commuting.

In contrast, technical options for the building stock are available and can be implemented at the municipal level for both the building energy supply and the building stock materials. Possible measures comprise the extension of the existing district heating network or financial support for private refurbishment initiatives aimed at both replacing fossil-fuel-based heating systems or at decreasing heating demand by improved insulation. The possibility of tightening the regulations for building design to some extent might also be taken into consideration. Changing the building energy system could affect around 70\% of the direct emissions from local residential energy demand (see figure 2), but also affects embodied, direct, and exported GHG in the areas of services: leisure activities and communications, local trade and industry (e.g., hotels, restaurants, and offices), as well as public services, education, and health care.

\section{Consumer-Driven Areas}

Consumer behavior dictates large parts of the GHG emissions in different areas of the CBF, including mobility, food consumption (nutrition), consumables, services: leisure activities and communications, and residential energy. In view of figure 2 , a special focus should be laid on the areas of mobility, food consumption, and residential energy.

Influencing and changing behavioral patterns can be challenging, but will be necessary in order to achieve a sustainable level of GHG emissions. Some options, such as raising awareness and financial incentives, have already been mentioned. Raising awareness of sustainable consumption can be achieved by organizing information events, distributing leaflets or by setting up an information center. A successful reduction of GHG emissions depends on local consumers assuming responsibility for their consumption patterns.

\section{Areas of Supraregional Importance}

As mentioned above, many aspects are beyond the control of a Swiss municipality. For instance, agriculture belongs to domains that are mainly regulated at the national level. Regardless, mitigating GHG from agricultural activities in Zernez would be difficult, given that Alpine livestock farming is the nearly only feasible and economically viable agricultural activity in Zernez. In addition, eliminating meat and milk production in Zernez in an effort to reduce local GHG emissions may simply lead to the relocation of said activities rather than to overall emission savings, as long as the demand for meat and dairy products do not change. However, introducing regulations to alter livestock production practice could be an option from a pure GHG perspective. Nguyen and colleagues (2010) and Peters and colleagues (2010) found that intensive meat production systems tend to perform more efficiently than extensive ones with regard to GHG. However, a deepened analysis would 


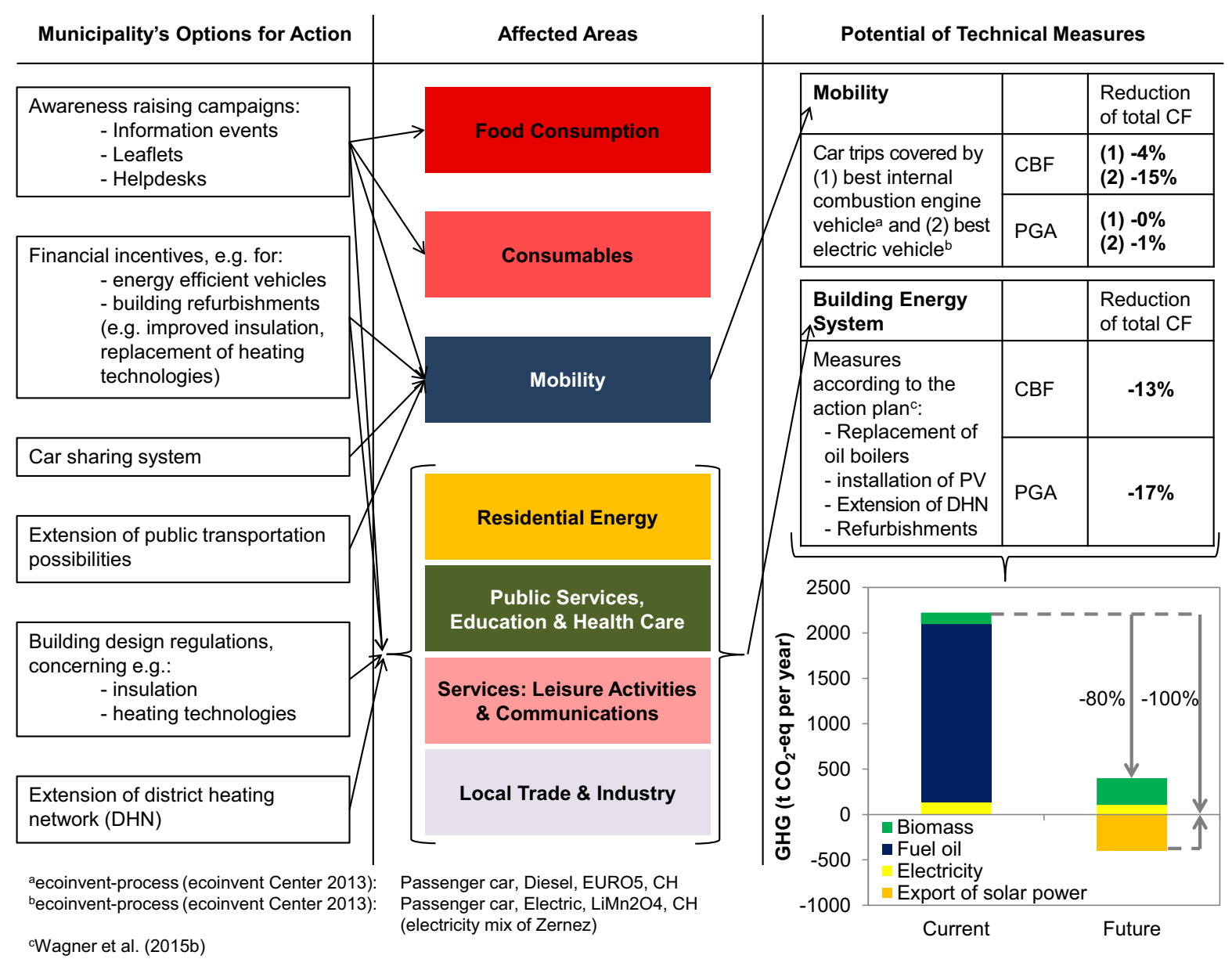

Figure 3 Overview of the municipality's areas of action, which are mentioned in the text. Rough estimates for two extreme mobility scenarios were conducted (replacing all car trips by the best internal combustion engine vehicle and the best electric vehicle, respectively). The reduction potential of technical measures in the building sector was extracted from Wagner and colleagues (20I5a, 20I5b). Bottom right corner: Simplified illustration of the current and the predicted community-wide infrastructure footprint of the building stock's energy demand (see text for more information) and contributing energy carriers (Wagner et al. 20I5b). CBF = consumption-based footprint; $\mathrm{CF}=$ carbon footprint; PGA = purely geographical accounting; PV = photovoltaics.

be required to assess whether these study results also apply to the prevailing circumstances in Zernez. Nguyen and colleagues (2010) further indicate that targeted feeding strategies might minimize enteric $\mathrm{CH}_{4}$ emissions and improved manure management could decrease $\mathrm{N}_{2} \mathrm{O}$ emissions.

The municipality of Zernez and its inhabitants have only a limited scope of action available to reduce GHG in domains such as public services or health care. Local authorities account for only a minor contribution to GHG emissions in this area. Therefore, the largest potential is at cantonal and national levels, for example, through federal programs (Schweizerische Eidgenossenschaft 2013; RUMBA 2015).

\section{Overview of Areas of Action}

Figure 3 gives an overview of all above-mentioned options for action. In addition, rough estimates of theoretical reduction potentials, which can be achieved by implementing technical measures, are also shown.
The discussion above reveals that it is generally difficult to adopt GHG reduction strategies at the municipal level given that many GHG areas are behavior driven or need to be tackled at a supraregional scale. The municipality of Zernez decided to focus on the CF of the building stock's energy demand as a first step. This is a reasonable starting point given that Swiss municipalities are in the position of setting financial incentives, providing helpdesks, and also have the ability to adopt new building design regulations. In addition, they often own energy utilities (e.g., electrical power supply or district heating networks).

\section{Derivation of Targeted Measures}

For the assessment of the $\mathrm{CF}$ and for the identification of GHG reduction potentials, the present study focused on the PGA and CBF because these two accounting methods allow for consistently assessing each category and complement each 
other in an easily understandable way (cf. figure 2). However, for the derivation of measures targeted at the optimization of infrastructure, such as the building energy system, a "trans-boundary community-wide infrastructure" footprint (CIF) is more appropriate (Chavez and Ramaswami 2013; Lin et al. 2015). The Supporting Information on the Web provides information on the determination of the CIF for the building energy system in Zernez as well as a detailed flow scheme and a table showing the current energy flows related to the building stock.

Taking the CIF as a concrete planning basis to reduce GHG from the operation of the building stock, the municipality and its inhabitants entered an extensive stakeholder engagement process in the scope of the research project Zernez Energia 2020 (Wagner et al. 2015a, 2015b). The project used an interdisciplinary approach to integrate building optimization options, renewable energy production, and urban planning. Additionally, the municipal authorities, the residents, and private companies were involved to include socioeconomic aspects of technical measures. Based on this transdisciplinary process, an action plan was developed for Zernez to mitigate GHG emissions caused by building energy demand (Wagner et al. 2015b). Measures include replacement of oil boilers, extension of the district heating network, installation of PV cells, and targeted refurbishments of specific buildings and building components. The implementation of all of the proposed actions is forecasted to decrease the CIF of the building stock from the current value of approximately 2,225 to approximately $400 \mathrm{t} \mathrm{CO}_{2}$-eq/yr for an $80 \%$ emission reduction (see bottom right corner in figure 3 ). The project Zernez Energia 2020 intends to compensate for these remaining emissions by exporting low carbon solar power to the national grid. By achieving a " $\mathrm{CO}_{2}$-neutrality" for the building stock, total embodied emissions could decrease by $3 \%$, total direct emissions from local demand by $76 \%$, and exported emissions by $8 \%$ (percentages are related to figure 2 ). This equals a reduction of the total footprint by $13 \%$ for the CBF and by $17 \%$ for the PGA, respectively (figure 3 ).

\section{Limitations of the Study}

The presented approach to quantify the CF of Zernez involves many assumptions. Although the assessment of the GHG emissions was conducted with due care, the presented results contain uncertainties for example, attributed to simplifications, estimations, or inaccurate data. However, a lack of uncertainty information in the collected data hindered performing a detailed uncertainty analysis. Nevertheless, it has to be emphasized that the present study is based on a data set that is unique in its detail. This data set allowed for deducing results that provide a clear order of magnitude of the different categories and uncover how these different areas perform compared to one another.

Further, global warming is just one environmental concern of several. Besides different global-level indicators, local environmental impacts also need consideration given that they directly affect local living conditions and can also provide feedback to the functioning of the Earth system as a whole (Steffen et al. 2015; Rockström et al. 2009). GHG emissions illustrate the main focus of the project Zernez Energia 2020 because global warming tops the political discussion regarding environmental impacts. However, recommendations for sustainable measures require a holistic perspective and should thus take different environmental indicators into account. For example, a large share of buildings in Zernez are heated by direct electricity or woodbased systems (wood logs or wood chips), both of which are lowcarbon technologies. But the former wastes high-quality energy for low-quality purposes and thus prevents a more-efficient energy use, whereas the latter may cause significant emissions of particulate matter (Szidat et al. 2007), which may lead to serious health damage ranging from asthma to respiratory illness and lung cancer. Technical measures to reduce these emissions need to be implemented as well. Moreover, biogenic $\mathrm{CO}_{2}$ emissions from wood-based heating systems were not considered in the presented CF, although they might have an impact on the global climate in the short term (Cherubini et al. 2011).

\section{Conclusions and Outlook}

The transformation of the building stock, especially of the energy supply system, was identified as a field of action for Swiss municipalities. The implementation of the action plan (Wagner et al. 2015b) will lead to a significant reduction of GHG in Zernez and will increase the shares of renewable energy sources. Albeit these building-stock-oriented measures need to be followed by further action in other sectors, it is already a good step forward and might act as an example for other rural or Alpine municipalities. In the present case of Zernez, the current CF of the building stock is already below the national average, meaning the reduction potential may be higher in other Swiss municipalities.

However, the purpose of this article is not to compare Zernez with other municipalities. Detailed household- and buildinglevel data are available for Zernez, but no other municipality possesses a comparable database. Whereas this unique data set enabled the exemplification of how a rural community can quantify and reduce its GHG emissions, we attempt to develop a detailed bottom-up consumption model based on nation-wide data in follow-up research. This model will build upon the ideas of Saner and colleagues (2013) and on the detailed insights of the present study. The planned model will allow for computing the CBF on different aggregation levels and will thus enable comparisons between different municipalities and cities. Further, it shall support the development of targeted measures also in Swiss municipalities with less data available than Zernez.

\section{Acknowledgments}

We thank the project team of Zernez Energia 2020, especially the municipality of Zernez, for the fruitful collaboration and the inhabitants and utility operators who provided important information through interviews. Our thanks also go to the research team for valuable inputs in general. In this context, we give a 
special mention to the project coordinator, Michael Wagner. We also thank Franziska Stoessel, Stephan Pfister, and Christie Walker for their important inputs and Marie-Christin Weber for her assistance. The research presented here is funded by CTI (Zernez Energia 2020, No. 15042.1).

\section{References}

ARE (Amt für Raumentwicklung), Amt für Energie und Verkehr, Amt für Natur und Umwelt, Amt für Wirtschaft und Tourismus, Tiefbauamt, and Verkehrsplanung Stadt Chur. 2012. Mobilität in Graubünden-Ergebnisse des Mikrozensus Mobilität und Verkehr 2010 [Mobility in the canton of Grisons-Results of the Mobility and Transport Microcensus 2010]. Chur, Switzerland: Amt für Raumentwicklung.

ASTRA (Bundesamt für Strassen). 2014. Verkehrsdaten. [Traffic data]. www.astra.admin.ch/verkehrsdaten/index.html. Accessed April 2014.

AWT (Amt für Wirtschaft und Tourismus Graubünden). 2010. Ständige Wohnbevölkerung nach Eckwerten, Gemeinden. Volkswirtschaftliche Grundlagen. Graubünden [Resident population statistics for different parameters and municipalities. Economic basic information. Canton of Grisons]. Chur, Switzerland: Amt für Wirtschaft und Tourismus.

Balmer, M., K. W. Axhausen, and K. Nagel. 2006. Agent-based demand-modeling framework for large-scale microsimulations. Transportation Research Record: Journal of the Transportation Research Board 1985(1): 125-134.

Baynes, T., M. Lenzen, J. K. Steinberger, and X. Bai. 2011. Comparison of household consumption and regional production approaches to assess urban energy use and implications for policy. Energy Policy 39(11): 7298-7309.

Baynes, T. M. and T. Wiedmann. 2012. General approaches for assessing urban environmental sustainability. Current Opinion in Environmental Sustainability 4(4): 458-464.

BFS (Bundesamt für Statistik). 2011. Reisen der Schweizer Wohnbevölkerung 2010 [Travels of the Swiss resident population 2010]. Neuchâtel, Switzerland: Bundesamt für Statistik (BFS).

BFS (Bundesamt für Statistik). 2012. Haushaltsbudgeterhebung 2010: Kommentierte Ergebnisse und Tabellen [Household budget survey 2010: Commented results and tables]. Neuchâtel, Switzerland: Bundesamt für Statistik (BFS).

BFS (Bundesamt für Statistik). 2014a. STATPOP 2013-Statistik der Bevölkerung und Haushalte [Statistics of the population and households of Switzerland 2013]. Neuchâtel, Switzerland: Bundesamt für Statistik (BFS).

BFS (Bundesamt für Statistik). 2014b. Die Raumgliederungen der Schweiz 2014 [Spatial structures of Switzerland 2014]. Neuchâtel, Switzerland: Bundesamt für Statistik (BFS).

BFS (Bundesamt für Statistik). 2014c. STAT-TAB: Die interaktive Statistikdatenbank [The interactive database of the Federal Statistical Office]. Neuchâtel, Switzerland: Bundesamt für Statistik (BFS).

BFS (Bundesamt für Statistik). 2014d. Physische KontenMaterialflüsse [Physical accounts - material flows]. www.bfs.admin. ch/bfs/portal/de/index/themen/02/05/blank/data/03/01.html. Accessed April 2014.

Büsser, S. and N. Jungbluth. 2009. The role of flexible packaging in the life cycle of coffee and butter. The International Journal of Life Cycle Assessment 14(1): 80-91.
Chavez, A. and A. Ramaswami. 2013. Articulating a trans-boundary infrastructure supply chain greenhouse gas emission footprint for cities: Mathematical relationships and policy relevance. Energy Policy 54: 376-384.

Cherubini, F., G. P. Peters, T. Berntsen, A. H. Strømman, and E. Hertwich. 2011. $\mathrm{CO}_{2}$ emissions from biomass combustion for bioenergy: Atmospheric decay and contribution to global warming. GCB Bioenergy 3(5): 413-426.

ecoinvent Center. 2013. ecoinvent data, version 2.2. 1998-2013. www.ecoinvent.org/database/. Accessed June 2014.

Eurostat. 2016. RAMON-Reference And Management of Nomenclatures. http://ec.europa.eu/eurostat/ramon/miscellaneous/ index.cfm?TargetUrl=DSP_DEGURBA. Accessed August 2016.

Filli, I. A. 2014. Personal communication with I. A. Filli, Operator of the waste water treatment plant in Zernez, Switzerland.

Frischknecht, R., C. Nathani, S. Büsser Knöpfel, R. Itten, F. Wyss, and P. Hellmüller. 2014. Development of Switzerland's worldwide environmental impact. Environmental impact of consumption and production from 1996 to 2011. Bern, Switzerland: Federal Office for the Environment (FOEN).

Froemelt, A. and S. Hellweg. 2016. Assessing space heating demand on a regional level: Evaluation of a bottom-up model in the scope of a case study. Journal of Industrial Ecology. https://doi.org/ $10.1111 /$ jiec. 12438

GastroSuisse. 2012. Branchenspiegel 2012 ["Mirror of the industry"Status quo report on the Swiss gastronomy sector]. Zurich, Switzerland: GastroSuisse.

Goldstein, B., M. Birkved, M. Quitzau, and M. Hauschild. 2013. Quantification of urban metabolism through coupling with the life cycle assessment framework: Concept development and case study. Environmental Research Letters 8(3): 35024-35024.

Grass, F. 2014. Personal communication with F. Grass, Operator of the biogas plant in Zernez, Switzerland.

Hertwich, E. G. and G. P. Peters. 2009. Carbon footprint of nations: A global, trade-linked analysis. Environmental Science $\mathbb{E}$ Technology 43(16): 6414-6420.

Hillman, T. and A. Ramaswami. 2010. Greenhouse gas emission footprints and energy use benchmarks for eight cities. Environmental Science Ë Technology 44(6): 1902-1910.

IPCC (Intergovernmental Panel on Climate Change). 2007. Climate change 2007: The physical science basis. Contribution of Working Group I to the Fourth Assessment Report of the Intergovernmental Panel on Climate Change. Cambridge, UK; New York: Cambridge University Press.

Jungbluth, N., R. Itten, and M. Stucki. 2012. Umweltbelastungen des privaten Konsums und Reduktionspotenziale [Environmental impacts of private consumption and reduction potentials]. Uster, Switzerland: ESU-services $\mathrm{GmbH}$

Jungbluth, N., C. Nathani, M. Stucki, and M. Leuenberger. 2011. Environmental impacts of Swiss consumption and production. A combination of input-output analysis with life cycle assessment. Bern, Switzerland: Federal Office for the Environment (FOEN).

Jungbluth, N., R. Steiner, and R. Frischknecht. 2007. Graue Treibhausgas-Emissionen der Schweiz 1990-2004. Erweiterte und aktualisierte Bilanz [Embodied greenhouse gas emissions of Switzerland 1990-2004. Extended and updated balance]. Bern, Switzerland: Federal Office for the Environment (FOEN).

Kennedy, C., J. Steinberger, B. Gasson, Y. Hansen, T. Hillman, M. Havranek, D. Pataki, A. Phdungsilp, A. Ramaswami, and G. V. Mendez. 2010. Methodology for inventorying greenhouse gas emissions from global cities. Energy Policy 38(9): 4828-4837. 
Kennedy, C., J. Steinberger, B. Gasson, Y. Hansen, T. Hillman, M. Havránek, D. Pataki, A. Phdungsilp, A. Ramaswami, and G. Villalba Mendez. 2009. Greenhouse gas emissions from global cities. Environmental Science Ë Technology 43(19): 7297-7302.

Kennedy, C. A., N. Ibrahim, and D. Hoornweg. 2014. Low-carbon infrastructure strategies for cities. Nature Climate Change 4(5): 343-346.

König, A., N. Jungbluth, and G. Doublet. 2014. Treibhausgasbilanz verschiedener Ferienszenarien [Carbon footprint of various holiday scenarios]. Zurich, Switzerland: ESU-services GmbH.

Koordinationsgruppe RUMBA and Fachgruppe RUMBA. 2015. Umweltbericht 2015 der Bundesverwaltung. Berichtsperiode 20132014 [Environmental report 2015 of the Federal Administration. Reporting period 2013-2014]. Bern, Switzerland: Schweizerische Eidgenossenschaft.

Larsen, H. N. and E. G. Hertwich. 2010. Identifying important characteristics of municipal carbon footprints. Ecological Economics 70(1): 60-66.

Lin, J., Y. Hu, S. Cui, J. Kang, and A. Ramaswami. 2015. Tracking urban carbon footprints from production and consumption perspectives. Environmental Research Letters 10(5): 054001.

Meister, K., M. Balmer, F. Ciari, A. Horni, M. Rieser, R. A. Waraich, and K. W. Axhausen. 2010. Large-scale agent-based travel demand optimization applied to Switzerland, including mode choice. Paper presented at 12th World Conference on Transportation Research, 11-15 July, Lisbon, Portugal.

Minx, J., G. Baiocchi, T. Wiedmann, J. Barrett, F. Creutzig, K. Feng, M. Förster, P.-P. Pichler, H. Weisz, and K. Hubacek. 2013. Carbon footprints of cities and other human settlements in the UK. Environmental Research Letters 8(3): 035039.

Nguyen, T. L. T., J. E. Hermansen, and L. Mogensen. 2010. Environmental consequences of different beef production systems in the EU. Journal of Cleaner Production 18(8): 756-766.

Nielsen, P. H., A.-M. Nielsen, B. P. Weidema, R. Dalgaard, and N. Halberg. 2003. LCA food data base. www.lcafood.dk. Accessed June 2014.

Orehounig, K., G. Mavromatidis, R. Evins, V. Dorer, and J. Carmeliet. 2014. Towards an energy sustainable community: An energy system analysis for a village in Switzerland. Energy and Buildings 84: $277-286$.

Peters, G. M., H. V Rowley, S. Wiedemann, R. Tucker, M. D. Short, and M. Schulz. 2010. Red meat production in Australia: Life cycle assessment and comparison with overseas studies. Environmental Science $\mathcal{E}$ Technology 44(4): 1327-1332.

PostAuto. 2014. Liniennetze [Route network]. www.postauto.ch/ en/node/31788. Accessed May 2014.

Ramaswami, A., A. Chavez, and M. Chertow. 2012. Carbon footprinting of cities and implications for analysis of urban material and energy flows. Journal of Industrial Ecology 16(6): 783-785.

Ramaswami, A., A. Chavez, J. Ewing-Thiel, and K. E. Reeve. 2011. Two approaches to greenhouse gas emissions foot-printing at the city scale. Environmental Science Eु Technology 45(10): 4205-4206.

Ramaswami, A., T. Hillman, B. Janson, M. Reiner, and G. Thomas. 2008. A demand-centered, hybrid life-cycle methodology for cityscale greenhouse gas inventories. Environmental Science $\mathcal{E}$ Technology 42(17): 6455-6461.

Rockström, J., W. Steffen, K. Noone, A. Persson, F. Stuart Chapin III, E. F. Lambin, T. M. Lenton, et al. 2009. A safe operating space for humanity. Nature 461(7263): 472-475.

Saner, D. 2014. Personal communication with D. Saner, Politics and Social Responsibility, Post CH Ltd., Switzerland.
Saner, D., C. Beretta, B. Jäggi, R. Juraske, F. Stoessel, and S. Hellweg. 2016. FoodPrints of households. The International Journal of Life Cycle Assessment 21(5): 654-663.

Saner, D., N. Heeren, B. Jäggi, R. A. Waraich, and S. Hellweg. 2013. Housing and mobility demands of individual households and their life cycle assessment. Environmental Science $\mathbb{E}$ Technology 47(11): 5988-5997.

SBB (Schweizerische Bundesbahnen). 2014. SBB: Der grösste Bahnhof der Schweiz. [SBB: Switzerland's biggest station.] www.sbb.ch/home.html. Accessed May 2014.

Schweizerische Eidgenossenschaft. 2013. Leitlinien und Ziele für das Ressourcen- und Umweltmanagement der Bundesverwaltung (RUMBA) [Guidelines and goals of the resource and environmental management of the Federal Administration]. Bern, Switzerland: Schweizerische Eidgenossenschaft.

SOSA GERA SA. 2014. SOSA GERA SA Zernez [Gravel quarry company in Zernez]. www.sosagera.ch/php/sosa-gera-kisswerk-zernezschweiz.php. Accessed April 2014.

Steffen, W., K. Richardson, J. Rockström, S. Cornell, I. Fetzer, E. Bennett, R. Biggs, et al. 2015. Planetary boundaries: Guiding human development on a changing planet. Science 347(6223): 1259855.

Stoessel, F., R. Juraske, S. Pfister, and S. Hellweg. 2012. Life cycle inventory and carbon and water foodprint of fruits and vegetables: Application to a Swiss retailer. Environmental Science $\mathfrak{E}$ Technology 46(6): 3253-3262.

swisstopo (Bundesamt für Landestopografie). 2014. www.swisstopo. admin.ch. Accessed April 2014.

Szidat, S., A. S. H. Prévôt, J. Sandradewi, M. R. Alfarra, H.-A. Synal, L. Wacker, and U. Baltensperger. 2007. Dominant impact of residential wood burning on particulate matter in Alpine valleys during winter. Geophysical Research Letters 34(5): L05820.

TBA (Tiefbauamt Graubünden). 2011. Permanente Strassenverkehrszählung 2010 [Permanent road traffic census 2010]. Chur, Switzerland: Tiefbauamt Graubünden (TBA).

Thrane, M. 2006. LCA of Danish fish products-New methods and insights. The International Journal of Life Cycle Assessment 11(1): 66-74.

UN (United Nations). 2012. World urbanization prospects: The 2011 revision. New York: United Nations.

UN-HABITAT. 2011. Cities and climate change: Global report on human settlements. London: Earthscan.

Wagner, M., C. Weyell, K. Christiaanse, A. Mikoleit, S. Hellweg, A. Frömelt, B. Steubing, et al. 2015a. Zernez Energia 2020_Leitfaden [Research report on the project Zernez Energia 2020]. Zurich, Switzerland: Eidgenössische Technische Hochschule Zürich (ETHZ).

Wagner, M., C. Weyell, K. Christiaanse, A. Mikoleit, S. Hellweg, A. Frömelt, B. Steubing, et al. 2015b. Zernez Energia 2020Aktionsplan. [Zernez Energia 2020_Action plan]. Zurich, Switzerland: Eidgenössische Technische Hochschule Zürich (ETHZ).

WRI (World Resources Institute) and WBCSD (World Business Council for Sustainable Development). 2004. The Greenhouse Gas Protocol-A corporate accounting and reporting standard. Greenhouse Gas Protocol. Geneva, Switzerland; Washington, DC: World Resources Institute (WRI) / World Business Council for Sustainable Development (WBCSD).

Zhang, X., L. Shen, and L. Zhang. 2013. Life cycle assessment of the air emissions during building construction process: A case study in Hong Kong. Renewable and Sustainable Energy Reviews 17: 160169. 


\section{About the Authors}

Andreas Froemelt is a Ph.D. candidate at the Swiss Federal Institute of Technology (ETH) in Zurich, Switzerland. Manuela Mauchle was a masters candidate at the Swiss Federal Institute of Technology (ETH) at the time the article was written. She is currently a project manager at $\mathrm{K}$. Lienhard AG (engineering company), Buchs-Aarau, Switzerland. Bernhard Steubing was a senior researcher at the Swiss Federal Institute of Technology (ETH) at the time the article was written. He is currently an assistant professor at the University of Leiden, Leiden, Netherlands. Stefanie Hellweg is a professor at the Swiss Federal Institute of Technology (ETH).

\section{Supporting Information}

Supporting information is linked to this article on the JIE website:

Supporting Information S1: This supporting information includes the following: (1) a map of Zernez Municipality; (2) details on the household consumption model of Saner and colleagues (2013); (3) a comparison of the consumption-based carbon footprint (CBF) of Zernez with the national CBF of Switzerland; (4) tables and Sankey diagram showing energy flows within the Zernez building stock; (5) a description of the derivation of the trans-boundary community-wide infrastructure footprint (CIF) for the Zernez building energy system; (6) a description of the bottom-up data from Wagner and colleagues (2015); (7) a description of data from enterprises located within the geographical system boundaries; and (8) detailed list of activities modeled for the greenhouse gas emissions assessment as well as (9) an overview of emission classification assumptions. 